\title{
Beagle 2: The Astrobiology Lander on ESA's Mars Express Mission
}

\author{
M.R. Sims ${ }^{a}$, C.T. Pillinger ${ }^{b}$, on behalf of the Beagle 2 consortium \\ ${ }^{a}$ Dept. of Physics and Astronomy, University of Leicester, University \\ Road, Leicester LE1 YRH, U.K. \\ ${ }^{b} P S R I$, Open University, Milton Keynes, MK7 6AA, UK
}

\begin{abstract}
Due for launch in 2003 as part of the Mars Express mission, the primary goal of the Beagle 2 lander is the detection of extinct or extant life on Mars. Atmospheric studies, analysis of subsurface material and regime, and the first attempt at in-situ radiometric dating of rocks on another planet make Beagle 2 unique among planetary missions. The lander is named after Darwin's ship, H.M.S Beagle.
\end{abstract}

Beagle 2 (Fig. 1, left) will examine the mineralogy and chemistry of rocks and soils within reach of the PAW, an integrated collection of instruments deployed by a $0.7 \mathrm{~m}$ long arm (Fig. 1, right). Samples acquired by the PAW will be delivered to the Gas Analysis Package (GAP) for isotopic analysis. Beagle 2 will attempt to date rocks in-situ via the $\mathrm{K}$-Ar method with data from the $\mathrm{X}$-ray spectrometer $\left({ }^{40} \mathrm{~K}\right)$ and the GAP $\left({ }^{40} \mathrm{Ar}\right)$. An Environmental Sensor Suite measures quantities including atmospheric pressure, wind speed and radiation levels at the landing site. The $60 \mathrm{~kg}$ lander $(9 \mathrm{~kg}$ of which is instrumentation) is due to reach the Martian surface in December 2003 in an airbag-assisted landing, and has an operational lifetime of 180 Sols. The prime landing site is Isidis $\left(270^{\circ} \mathrm{W} 12^{\circ} \mathrm{N}\right)$, an area which may have experienced influx from fluvial and mud flow mechanisms. The Beagle 2 Operations centre will be based at the National Space Science Centre in Leicester (UK).
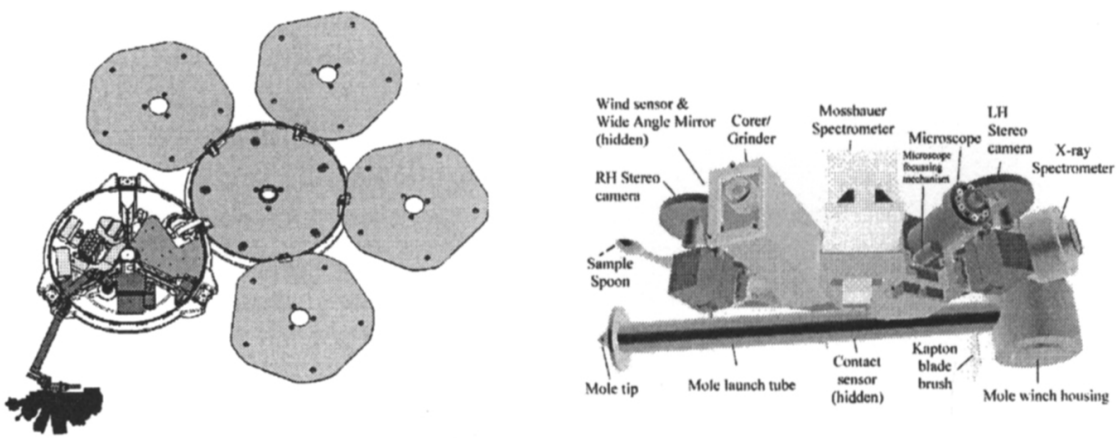

Figure 1. Left: Beagle 2 lander. Right: PAW instrumentation. 